\title{
HS-FCC High-severity fluidized catalytic cracking: a newcomer to the FCC family
}

\author{
R. S. Parthasarathi $\cdot$ Sarah S. Alabduljabbar
}

Received: 10 June 2014/ Accepted: 20 August 2014/Published online: 17 September 2014

(C) The Author(s) 2014. This article is published with open access at Springerlink.com

\begin{abstract}
High-severity fluid catalytic cracking (HSFCC) is a breakthrough technology in the refining and petrochemicals industry. It allows refineries to produce petrochemicals from heavy oils by converting a low-value refinery stream into high-value products, suitable for integrated processes. The process's main operating features are the down flow reactor system, high reaction temperature, short residence time, and high catalyst-to-oil $(\mathrm{C} / O)$ ratio with a modified separator system. The unique down flow reactor system in the HS-FCC process ensures plug flow without back-mixing, allowing more selectivity toward light olefins. HS-FCC produces four times more light olefins (propylene and butene) and higher octane gasoline than conventional FCC units. Since 1999, the HS-FCC has successfully passed several phases of testing with different types of feedstock at various feed capacities. The process has been proven in a 30 barrel per day (bpd) demonstration plant at Ras Tanura Refinery, Saudi Arabia. In 2011, a 3,000 BPD HS-FCC semi-commercial plant started operating at JX Mizushima Refinery in Japan. The unit ran successfully, meeting all design objectives. A full-scale commercial unit study for a 30,000 BPD HS-FCC plant was completed by JX and Chiyoda for HS-FCC commercialization.
\end{abstract}

R. S. Parthasarathi $(\bowtie)$

Saudi Aramco, P.O Box 8653, Dhahran 31311,

Kingdom of Saudi Arabia

e-mail: rengamannar.parthasarathi@aramco.com

S. S. Alabduljabbar

Saudi Aramco, P.O Box 1991, Dhahran 31311,

Kingdom of Saudi Arabia

e-mail: sarah.alabduljabbar@aramco.com
Keywords Fluid catalytic cracking · High-severity · Down flow reactor $\cdot$ Light olefins $\cdot$ Propylene

\section{Introduction}

Fluid catalytic cracking (FCC) units currently account for $30 \%$ of the worldwide propylene production with the remaining produced from ethylene steam cracking of light hydrocarbons and naphtha feedstocks. FCC propylene demand will continue to grow as the percentage of steam cracker propylene decreases as a result of an increase in ethane-based cracking [1]. While propylene is a normal product of the FCC process, conventional FCC operations target maximum gasoline yields and do not maximize propylene production. Today, new project developers demand product flexibility and process integration with petrochemical facilities for a greater profit. The HighSeverity Fluid Catalytic Cracking (HS-FCC) technology, developed by Saudi Aramco and their partners, can substantially increase the propylene yield compared to conventional FCC units. The HS-FCC process can satisfy the high propylene demand from a variety of feedstocks and provide high-octane catalytic cracker gasoline. Figure 1 illustrates the yield advantages associated with HS-FCC vs. the conventional and high-propylene FCC units.

Generally, various reactions such as catalytic cracking, thermal cracking, hydrogen transfer, isomerization and condensation reactions occur in the FCC reactor. Catalytic cracking is preferred over thermal cracking for maximum propylene production. As the severity of the FCC increases, liquefied petroleum gas (LPG) and propylene production increase as well. Therefore, maximum propylene production in FCC units is achieved by operating at high reaction temperature, short residence time and high catalyst-to-oil 


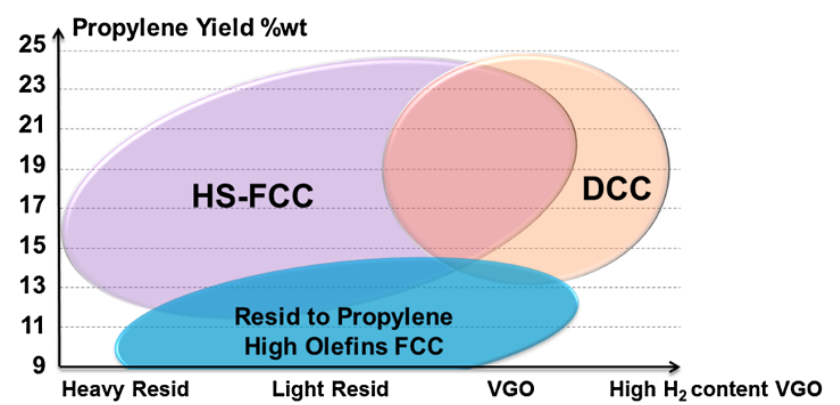

Fig. 1 Propylene yield and feed range for FCC processes

$(\mathrm{C} / \mathrm{O})$ ratio for a given feed and catalyst system. Catalyst back-mixing occurs in conventional FCC up-flow reactor systems, where the catalyst rises upwards by drag forces of the vaporized hydrocarbons, thereby allowing for the production of undesirable by products [2].

Experimental runs were conducted in a down flow and riser-type pilot plants and a demonstration plant using various catalysts, additives and feedstocks. The results demonstrated the advantage of the down flow technology to suppress back-mixing and reduce thermal cracking reactions, thereby increasing the yield of light olefins (ethylene, propylene and butylenes) while minimizing dry gas and coke yields despite the high operating temperatures [3]. Using paraffinic crude based vacuum gas oil (VGO) feed and proprietary ultrastable Y-type (USY) FCC catalyst, propylene yield of $25 \mathrm{wt} \%$ (feed basis) and gasoline yield of $30 \mathrm{wt} \%$ were obtained under HS-FCC reaction conditions [4]. Increasing the yield of the valuable light olefins, especially propylene and butenes, is a profitable opportunity for integrated refineries. As global petrochemical demand for propylene continues to grow, opportunities for improved production routes will emerge. Propylene is used as a feedstock for a wide range of polymers, product intermediates, chemicals and derivatives. The processing of propylene to polypropylene improves refinery margins and increases revenues because of the high value of polypropylene.

\section{Background}

Saudi Aramco, in partnership with JX Nippon Oil \& Energy, King Fahd University of Petroleum and Minerals (KFUPM), has successfully developed the HS-FCC technology in 1996. The main objective of the HS-FCC technology is to enhance propylene yields and gasoline octane number. HS-FCC propylene yield of $25 \mathrm{wt} \%$ was achieved as compared to $11 \mathrm{wt} \%$ propylene yield from conventional high propylene FCC units available in the market now.
Starting from 1999, the HS-FCC has successfully passed several phases of testing at various feed capacities at a pilot plant level $(0.1 \mathrm{bpd})$, demonstration plant level (30 bpd), and cold flow models (30 bpd and $500 \mathrm{bpd})$. In 2011, the 3,000 bpd HS-FCC semi-commercial plant started operating at JX Mizushima Refinery in Japan. Figure 2 illustrates the HS-FCC project milestones to date [5].

\section{HS-FCC technology}

HS-FCC technology is a state-of-the-art FCC technology that produces significant amounts of propylene and highoctane gasoline. At high-olefins mode of operations, the unit produces four times more light olefins with minimum gasoline loss compared to the conventional FCC process. HS-FCC technology operates under high reaction temperatures, short residence time and high $C / O$ ratio using a down flow reactor concept. Figure 3 illustrates the HS-FCC technology arrangement and catalyst flow.

\section{Reaction condition}

\section{High reaction temperature}

HS-FCC operates under severe reaction temperatures to allow for high selectivity toward propylene and butenes in the presence of proprietary catalysts. Elevated temperatures of approximately 550 to $600{ }^{\circ} \mathrm{C}$ enhance thermal and catalytic cracking [2]. Thermal cracking contributes to the formation of dry gas and coke while catalytic cracking increases olefin yield [6]. Raising the temperature also contributes in controlling the exothermic hydrogen transfer reaction.

\section{Short residence time}

A hydrocarbon short residence time $(<0.5 \mathrm{~s})$ is used to mitigate thermal cracking and therefore reduces dry gas and coke yields [2]. The short residence time also suppresses undesirable secondary reactions such as hydrogentransfer reactions, which consume olefins-to maximize propylene production. To ensure short residence times are achievable, a high efficiency/fast separator is designed to provide a sharp separation between the hot regenerated catalyst and hydrocarbon vapors, thereby minimizing dry and coke yields. Figure 4 illustrates the unique HS-FCC injector/separator system. 
Fig. 2 HS-FCC project milestones

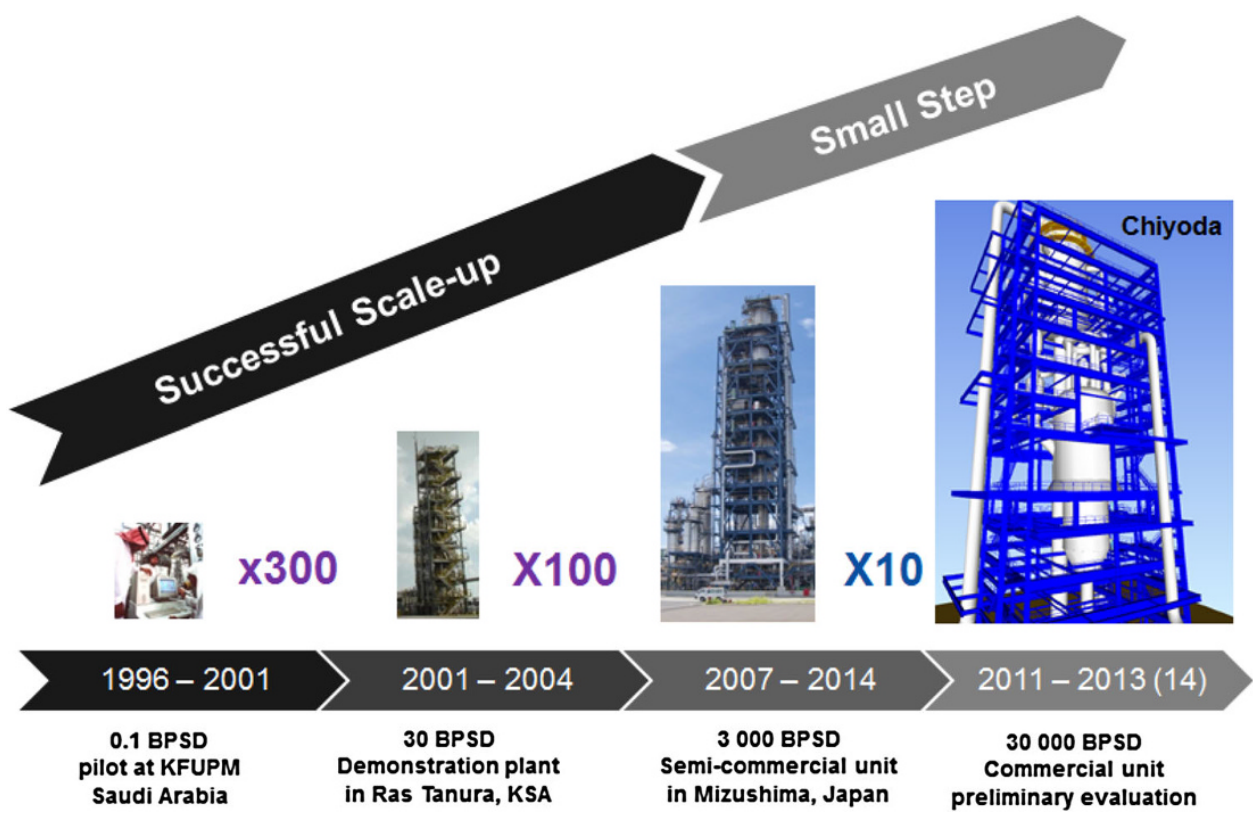

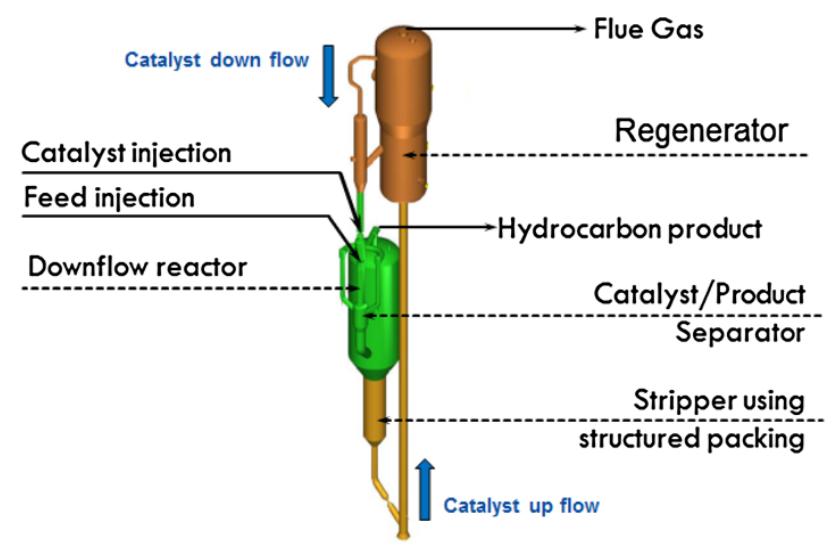

Fig. 3 HS-FCC technology

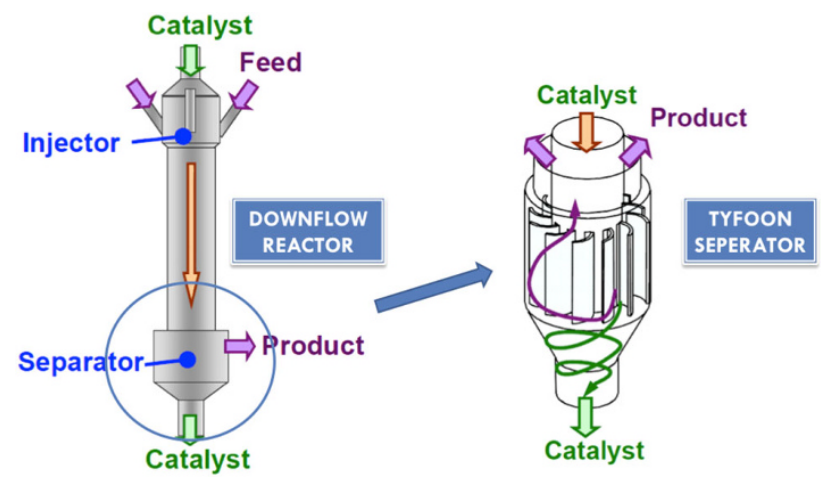

Fig. 4 HS-FCC injector and separator (TYFOON) system

High $\mathrm{C} / \mathrm{O}$ ratio

Due to the severe reaction temperatures and short contact time, higher catalyst circulation is required to achieve high

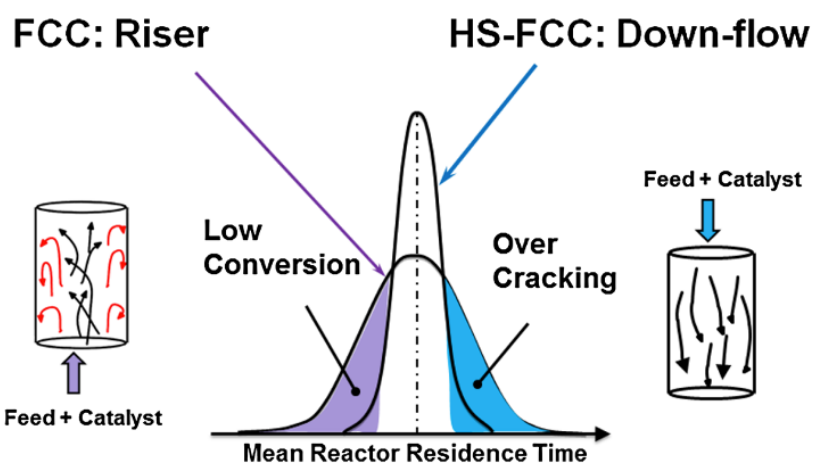

Fig. 5 Conventional FCC riser compared to HS-FCC down flow

conversions [2]. A $C / O$ ratio of approximately 20 to 30 minimizes the effects of operating at high reaction temperature (thermal cracking) by supplying more heat from its regenerator to reactor section to attain the heat balance. Also, increasing the $\mathrm{C} / \mathrm{O}$ ratio improves selectivity and conversion by enhancing catalytic reaction over thermal reaction.

\section{Down flow reactor system}

In riser reactor systems, the catalyst flows upwards by drag forces from the vaporized hydrocarbons. Operating under high $C / O$ ratio conditions typically results in back-mixing and reflux along the walls in conventional FCC riser reactors, particularly in the feed injection or catalyst pickup zone at the bottom of the reactor. This problem is overcome in down flow reactor systems, where both the catalyst and feed flow downwards together with gravity by achieving plug flow without back-mixing, thus allowing for short residence time [2]. Therefore, the HS-FCC's 


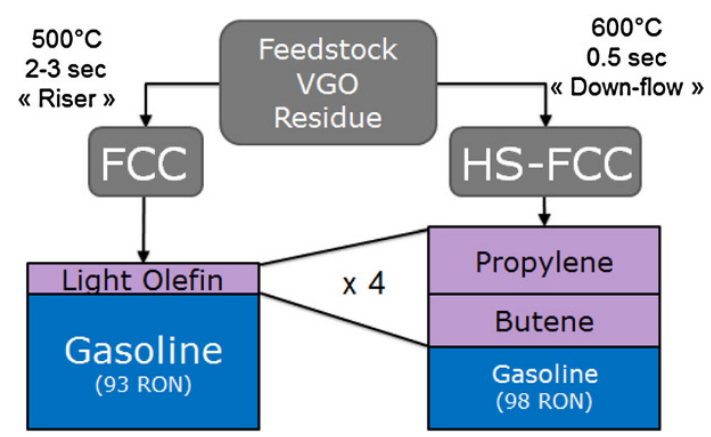

Fig. 6 HS-FCC vs. conventional FCC

breakthrough down flow reaction system allows maximum olefins production and reduces undesirable by products. Figure 5 illustrates the reactor residence duration for FCC riser vs. the HS-FCC down flow reactor.

\section{Catalyst system}

A catalytic system involving ultra-low hydrogen transfer was designed for the HS-FCC process to maximize olefins production. The HS-FCC catalyst uses a high USY zeolite content system with low acid site density to suppress hydrogen transfer and isomerization reactions, therefore allowing for high olefin selectivity [2]. Coupling the catalyst with ZSM-5 additives can maximize propylene production.

Figure 6 summarizes the yields and design features between HS-FCC and conventional FCC.

\section{Semi-commercial unit}

The JX Mizushima refinery started operating in May 1961 and has a total capacity of $345,000 \mathrm{bpd}$. The 3,000 bpd semi-commercial HS-FCC unit has been operating in Mizushima since 2011. The objective of the unit was to confirm yields, demonstrate operability and reliability, confirm scale-up criteria, and validate benefits of the HSFCC technology. The unit met all the objectives and its results were very encouraging. The HS-FCC propylene yield that was achieved was close to $20 \mathrm{wt} \%$. The HSFCC technology has been tested with various feedstocks at different capacities. The process ran with the following feeds: Hydrotreated VGO, mix of $60 \%$ hydrotreated VGO and $40 \%$ hydrotreated atmospheric residue (AR), mix of hydrocracker bottom and VGO, and mix of $81 \%$ hydrotreated atmospheric residue and $19 \%$ VGO. Each run was followed by a shutdown period for inspection. A long-term operation on $\sim 100 \% \mathrm{AR}$ is currently ongoing ( $\sim 1$ year) to fully assess the mechanical reliability of the system.

\section{Conclusions}

The HS-FCC technology achieves high propylene yields and high-octane number gasoline by utilizing a down flow reactor system, severe reaction conditions and an optimized catalyst system. Using paraffinic crude base VGO, propylene yield of $20 \mathrm{wt} \%$ was obtained under HS-FCC reaction conditions. The HS-FCC technology offers refinery petrochemicals integration opportunities for greater profits.

Open Access This article is distributed under the terms of the Creative Commons Attribution License which permits any use, distribution, and reproduction in any medium, provided the original author(s) and the source are credited.

\section{References}

1. Dean C (2013) Naphtha catalytic cracking for propylene production. Processing Shale Feedstock Magazine

2. Lambert N, Ogasawara I, Abba I, Redhhwi H, Santner C (2014) HS-FCC for propylene: concept to commercial operation

3. Abul-Hamayel MA (2004) Comparison of downer and riser based fluid catalytic cracking process at high severity conditions: a pilot plant study. Petrol Sci Technol 22(5):475-490. doi:10.1081/LFT120034183

4. Maadhah AG, Fujiyama Y, Redhwi, H, Abul-Hamayel M, Aitani A, Saeed, M, Dean C (2008) A new catalytic cracking process to maximize refinery propylene. Arab J Sci Eng 33(1B):17

5. Okazaki H, Tayyar M, Redhwi H, Roux R (2012) High severity fluidized catalytic cracking (HS-FCC)—go for propylene! In: 20th World Petroleum Congress, Doha

6. Redhwi H, Abul-Hamayel M, Maadhah A, Ino T, Fujiyama Y. Kleemeier K, Dean C, Al-Nemer M (2005) Meeting olefins demand in a novel FCC technology. In: 18th World Petroleum Congress, South Africa 